Board 12: Liberal Education/Engineering \& Society Division: Examining the Relationships Between How Students Construct Stakeholders and the Ways Students Conceptualize Harm from Engineering Design

\title{
Alexis Papak
}

Alexis Papak is a Research Assistant at the University of Maryland, College Park with the Physics Education Research Group. They completed their Bachelor's Degree in Engineering Physics at the University of Illinois at Urbana-Champaign. Their research interests are centered around how race and identity relate to STEM teaching and learning. 


\title{
Examining the Relationships Between How Students Construct Stakeholders and the Ways Students Conceptualize Harm from Engineering Design
}

\author{
Alexis Papak, University of Maryland, College Park
}

Alexis Papak is a Research Assistant at the University of Maryland, College Park with the Physics Education Research Group. They completed their Bachelor's Degree in Engineering Physics at the University of Illinois at Urbana-Champaign. Their research interests lie at the intersection of ethnic studies, critical pedagogies, and STEM teaching and learning.

\section{Dr. Ayush Gupta, University of Maryland, College Park}

Ayush Gupta is Assistant Research Professor in Physics and Keystone Instructor in the A. J. Clark School of Engineering at the University of Maryland. Broadly speaking he is interested in modeling learning and reasoning processes. In particular, he is attracted to micro-genetic and socio-cultural models of learning. He has been working on how learners' emotions are coupled with their conceptual and epistemological reasoning. Lately, he has been interested in engineering design thinking, how engineering students come to understand and practice design, and how engineering students think about ethics and social responsibility.

\section{Dr. Chandra Anne Turpen, University of Maryland, College Park}

Chandra Turpen is a research assistant professor in physics at the University of Maryland in the Physics Education Research (PER) Group. Turpen's work involves designing and researching contexts for learning within higher education (for both students and faculty). Her research draws from perspectives in anthropology, cultural psychology, and the learning sciences. Through in-situ studies of classroom practice and institutional practice, she focuses on the role of culture in science learning and educational change. She pursues projects that have high potential for leveraging equitable change in undergraduate STEM programs and she makes these struggles for change a direct focus of her research efforts. She also serves on several national leadership bodies: the Physics Education Research Leadership Organizing Council (PERLOC), the American Association of Physics Teachers' Committee on Diversity in Physics, the National Learning Assistant Alliance, and the Access Network. 


\title{
Examining How Engineering Students Construct Stakeholders and Perceive Harm in Sociotechnical Case Studies ${ }^{1}$
}

\begin{abstract}
Engineering ethics curriculum and the research around it often emphasizes micro-ethical issues such as whistle-blowing and responsible conduct of research with lesser but growing attention to macro-ethical issues such as how engineering practice is entangled with broader social, political, economic, and environmental concerns. Engaging in macro-ethical reasoning often requires conceptualizing a wide range of stakeholders and their concerns, challenging one's beliefs about engineering as naturally leading to social good, and conceptualizing negative impacts of engineering work. There is still a paucity of research on the moment-to-moment dynamics and evolution of students' macro-ethical reasoning in sociotechnical contexts. In this paper, we present analysis of audio-video data from a series of focus group sessions in which engineering students discuss the ethics and ethical implications of a 2012 incident in which statisticians and engineers at Target developed predictive analytical software capable of identifying shoppers who were pregnant. We show how students' conceptualization of different stakeholders was relational, in that the ways in which pregnant women were conceptualized was entangled with how Target was conceptualized. We also argue that the way students construct various stakeholders over three focus group sessions constrained how they were able to understand any of the stakeholders as causing harm or being harmed.
\end{abstract}

\section{Introduction}

Engineering ethics educators have developed a wealth of curricula that engages engineering students in learning about codes of ethics and micro-ethical issues. However, much of these curricula does not engage how technology's design and implementation is reflective of sociopolitical systems and never value-neutral or how ethical design requires foregrounding care and empathy for stakeholders (Herkert, 2005). Engineering's dominant "culture of disengagement" (Cech 2012, Slaton 2015) toward social responsibility makes it challenging for educators to develop courses that engage students in considering stakeholders empathetically. To counter this "culture of disengagement" and develop curricula that prepares students to engage in their profession with responsibility, empathy, and care, it is important that educators analyze how engineering students reason about the relationships between engineering practices and the possibilities for them causing harm. While researchers have begun examining the ways engineering students think about harm and violence with respect to engineering and engineering ethics (Lachney and Banks, 2017), less fine-grained analysis work has been done in examining how conceptions of harm occur in the moment-to-moment of engineering ethics discussions.

In this paper, we analyze video data from a series of focus group sessions centered around the 2012 case study in which statisticians and engineers at Target developed predictive analytics software capable of identifying pregnant women and new mothers (Duhigg, 2012). Engineering students read about the case of a young pregnant woman in high school whose father found out she was pregnant through expecting mother advertisements targeting her as a

\footnotetext{
${ }^{1}$ The first and second authors contributed equally to this work.
} 
result of Target's statistical software. Students then discussed the ethical implications of this case to engineering and engineering ethics over the course of three two-hour discussion sessions. We analyzed the ways that students ideologically construct various stakeholders in the case study such as Target and pregnant women.

From this analysis, we find that students don't construct the individual stakeholders in the case-study independently. Rather, students construct these stakeholders simultaneously and in relation to other stakeholders, and students form these constructions collectively through the joint action and dialogue. Additionally, the way students relationally constructed these stakeholders constrained the ways students were able to understand any one of the stakeholders as producing harm or being harmed. Some of the constructions that emerged reflect many of the assumptions built into the language of engineering ethics (e.g., engineers serve the advancement of society and the welfare of the public). This language reifies constructions of engineers as knowledgeable deliverers of public good and is especially problematic when engineers fail to represent the people they intend to impact. We also document how the emergent constructions in students' reasoning were context-sensitive, and when students were specifically asked to consider the harm that might come to someone from predictive analytics or asked to imagine specific harms that the pregnant woman in the case-study might potentially experience, participants were able to imagine alternative constructions of stakeholders.

\section{Literature Review}

Much of the curricula engineering educators have developed has focused on microethical issues such as designing safe products, not accepting bribes, and abiding as an individual to professional codes of ethics (Herkert, 2005). Herkert has described the need for curriculum that engages with macro-ethical concerns such as engineers' sociopolitical responsibility and consideration of how their practices affect multiple stakeholders. He has argued that considering these concerns is essential so that engineers can be given tools that will enable them to deal with complicated ethical issues that arise in their roles (Herkert, 2005).

Some scholars have begun examining the ways stakeholder perspectives and care ethics can be important in professional practice. Norcia (2002) has argued how social and cognitive diversity are crucial elements to solving complex, sociotechnical problems that engineers face. Campbell and Wilson (2017) have also documented a need for care ethics as a missing dimension in an engineering ethics not accounting for differences in power and dependence, showing how canonical curricula's focus on impartiality and standards does not prepare students to engage in care ethics.

Others have examined how engineering students understand engineers' social responsibility to public welfare and how students understand how engineering causes public harm. Cech (2012) has documented a "culture of disengagement" in engineering in which students' considerations of public welfare decrease over the course of their engineering education. This "culture of disengagement" is part of what Lachney and Banks (2017) have documented as the "neutrality problem" in engineering, where engineers and engineering students assume engineering knowledge production and practices are apolitical and valueneutral. In interviewing students for how they conceptualize violence, Lachney and Banks (2017) have found that while students were able to conceptualize how engineering can cause interpersonal violence through application of its designs, they often lacked the analytical tools to 
consider structural violence that did not clearly specify the subjects and objects of interpersonal violence. For example, while engineering students were able to consider how the application of engineering technology can cause violence, they struggled to engage with the politics of what engineering work is valued and who engineering designs serve or harm.

This paper seeks to add to this scholarship by producing an analysis of how students construct various stakeholders in a sociotechnical scenario, with particular attention to how these constructions inform students' understanding of harm from engineering in the context of the presented scenario. The analysis finds that (i) the individual stakeholder constructions do not emerge in isolation and are instead entangled with each other, forming an ecology in which each construction is informed by and informs the others; and (ii) these constructions strongly constrain how stakeholders are perceived as being harmed or causing harm.

\section{Data Collection and Analysis Methodology}

The research team recruited students for this study from engineering programs at a large public university to participate in a series of focus group sessions on the topic of sociotechnical issues. A mix of seven undergraduate and graduate engineering students self-selected to be a part of the study and participated in a total of twelve focus group sessions. All students who expressed interest were included in the focus group and they were compensated $\$ 10$ per hour for their time. For the focus group sessions discussed in this paper, all the participants identified as male.

Participants met for the focus group sessions on Sunday afternoons in a conference room on campus. The participants sat around a large rectangular table in the room, with the facilitators typically positioned at opposite ends of the table. The participants were provided with paper and pens, and post-it notes for writing their thoughts down (prompted or unprompted). The sessions were video recorded from two angles in order to capture the entire group and an additional audio recording was captured from a third part of the room. In addition to these recordings, facilitators took field notes throughout the sessions and collected participants' written materials at the end of each session.

The twelve focus group sessions centered on several sociotechnical issues ranging from predictive analytics to autonomous drone warfare. Gupta, Turpen, and co-researchers, Andrew Elby, Thomas Philip, and Daniel Dilliplane, participated in the design of the focus group prompts. The sessions were loosely structured with planned prompts and activities, but with enough flexibility that facilitators could make decisions about adding new prompts or letting students continue a conversation longer than intended. Ayush Gupta (Ayush) and Daniel Dilliplane (Dan) served as the facilitators for all the sessions. In addition to participating in these sessions, students were given supplemental materials to read between many sessions and given post-session surveys. The first focus group session focused on students getting to know each other, getting comfortable talking to each other, and an activity in which students engaged with how engineering design involves a network of stakeholders being impacted.

The case of Target using predictive analytics to target advertisements at pregnant women and new mothers was discussed in sessions two through four. These sessions were professionally transcribed and a content log was generated in order to code for major movements in the discussion and to identify segments of video for further analysis. Based on field notes, we knew 
that on the first day of discussing the Target case study, the participants minimally considered harm to the pregnant woman in the case-study, which surprised the facilitators. The prompts for the subsequent focus group sessions were designed to see if we could get participants to engage with greater empathy towards the pregnant woman, and how might such a shift influence the ways in which participants conceptualize engineers' roles and responsibilities. Our initial selection of segments was guided by this consideration.

It is important to note here that we view the reasoning that students engaged in (and the constructions that we document through our analysis) as, in part, a function of the conversational dynamics, facilitation prompts and structures, and institutional as well as broader national culture. While we don't want to discount individual students' agency in taking on the stances we highlight here, we worry about implicitly allowing for deficit views of the participants in our study, especially because in this paper we aren't able to model the contextual features or conversational dynamics. It is with this orientation in mind that we want readers to approach the findings and analysis.

As our analysis proceeded, and, in part, inspired by the work by Lachney and Banks (2017), we started to articulate research questions focused on conceptualizations of harm. Preliminary analysis suggested that these conceptualizations were entangled with the construction of stakeholders. Subsequently, we tagged segments of content log for when Target and pregnant women and new mothers were the focus of the conversation. Through additional research meetings and iterations of analysis, constructions of stakeholders and of harm became objects around which we fine-tuned the selection of segments and generated analytical memos. In our analysis, we worked through the selected transcript portions line by line to code for how women and Target were being constructed. Proximity of constructions and logical dependency in the reasoning were used as evidence to argue for how the constructions of different stakeholders are entangled. Interpretations in the analytical memos were iteratively revised several times through group discussions (Engle, Conant, and Greeno, 2007). Roughly, in this process, we had the following orientations: (1) we assumed context-dependence, in that we expected that constructions of stakeholders could change swiftly, (2) we attended to how multiple participants contributed to the constructions in any given local moment, (3) the descriptions of constructions were kept fairly low inference (for example, if a participant noted that Target was trying to help the customers by providing them coupons, then a corresponding construction would be "Target as benevolent").

Instead of discussing our analysis methods in the abstract, we present the analysis in great detail (especially in the first segment of the analysis) so that the reader can evaluate our interpretations. For the purpose of this paper, we selected four segments to support our claims empirically. A brief description of these segments are presented in Table 1. 
Table 1. A brief description of the segments included in the paper

\begin{tabular}{|l|l|l|l|}
\hline Segment & Focus Session & Duration & Rough content description of the segment \\
\hline Segment 1 & Session 2 & Minutes 5-13 & $\begin{array}{l}\text { Participants start discussing the Target case } \\
\text { study, mostly minimize harm to the pregnant } \\
\text { woman, except for consideration of loss of } \\
\text { privacy }\end{array}$ \\
\hline Segment 2 & Session 3 & Minutes 3-27 & $\begin{array}{l}\text { Participants are divided into two sub-groups } \\
\text { and are asked to imagine someone who } \\
\text { might be harmed by predictive analytics } \\
\text { based advertising campaigns; in one sub- } \\
\text { group they are prompted to flesh out the } \\
\text { details of how the harm will be manifested }\end{array}$ \\
\hline Segment 3 & Session 4 & Minutes 30-47 & $\begin{array}{l}\text { Participants are asked to imagine the } \\
\text { different ways in which the pregnant woman } \\
\text { in the case-study could be harmed through } \\
\text { the disclosure of her pregnancy to her family }\end{array}$ \\
\hline Segment 4 & Session 4 & Minutes 47-60 & $\begin{array}{l}\text { (Continuous with Segment 3); As } \\
\text { participants discuss the role of society and } \\
\text { imagine a more complex causality for the } \\
\text { disclosure event, they distance Target again } \\
\text { from accountability towards the disclosure } \\
\text { and harm resulting from it. The constructions } \\
\text { of stakeholders shift in this segment. }\end{array}$ \\
\hline
\end{tabular}

\section{Analysis}

\section{Segment 1}

The first segment of data we analyze in this paper is from minutes 5-13 of the second focus group session. In this session, the students begin discussing the case of Target advertising to pregnant women using predictive analytics. Before the session, students were asked to read the New York Times article "How Companies Learn Your Secrets," describing Target's use of predictive analytics and how a pregnant woman's family discovered she was pregnant through these targeted advertisements. The session was facilitated by Ayush and Dan, and all seven participants attended this session: Bill, Zafar, Rakesh, Rupert, Kwan, Feng, and John. Participant names are all pseudonyms. The segment begins with Ayush prompting the participants to describe what they thought the main point of the article was.

Bill was the first to respond to Ayush's prompt:

Bill: Does like anyone think it was an attack on Target, so to speak, like kind of felt like exposing their process? Because I don't know if I got that feel, but I was 
wondering if anyone else was thinking, like if it was meant to expose their shady business practices, if that was what it was for.

In responding to Ayush's question, Bill asks the group whether the article was an attack on Target meant to expose them. In making these suggestions, Bill uses moralized language such as "attack", and "expose" that set up an opposing relationship between Target and the article in which the article may be an aggressor and Target may be a victim. While Bill cautiously suggests this relationship without explicitly affirming it, Zafar vocalizes this idea much more strongly:

Zafar: It was written very critically, from the point of view of the customer who is very angry from knowing this. It wasn't like from someone who is looking at both sides. It was a one-sided thing, I think.

He points out in this turn of talk that the article was from the point of view of "an angry customer" and that it was one-sided. These vocalizations seem to merge the author of the article with a customer, and cast the article as emotional, untrustworthy, and opinionated, reinforcing the construction of Target as a victim being treated unfairly.

Another construction of Target emerges a few turns of talk later, beginning when Rakesh questions whether Target is at fault. Rakesh states:

Rakesh: Does anyone else feel what Target did wasn't wrong? ... I didn't really find much wrong in what they did, because they're just trying to - they're just keeping track of who is buying from their shop basically, and then they are trying to see how much. Just giving it, you know, a status take of how much each person is buying and what each person is buying, and then sending them ads related to the situation. But, I personally feel that there's nothing really wrong keeping track of what each person buys from your own shop. However, the privacy part, we can get to that later, but....

Rakesh asks if "anyone else feel[s] what Target did wasn't wrong" and stresses that he doesn't find much wrong with anything Target did, framing Target as innocent and having done nothing wrong. Rakesh also describes Target in a way that stresses Target as the rightful owner of customers' shopping data. He describes Target as a shop owner who is "just keeping track of who is buying from their shop" and goes on to describe how Target's collection of data is no different than what any small shop would do. Rakesh also repeatedly uses the word "just" in his statements, reinforcing how common-sense Target's collection of customer's data is. Through these statements, Target is constructed as being entitled to and the rightful owner of the data of who is shopping at its store and what they are buying.

Throughout his turn of speech, it is evident that Rakesh's construction of Target as the rightful owner of customers' data is strongly tied to his construction of Target as innocent. His use of the logical connector "because" frames his statements constructing Target as the rightful owner of customers' data as evidence of Target's innocence. There is more evidence of this mutual construction near the end of his utterance, when Rakesh states that "there's nothing really wrong keeping track of what each person buys from your own shop." Here, the phrase "there's 
nothing really wrong" is serving two purposes, both cementing the construction of Target as innocent and referring to the rightfulness of Target's use of customer's data.

In Rupert's next turn of talk, he responds to Rakesh and makes statements that construct Target as beneficent to new mothers. Rupert begins:

Rupert: I agree with you. I think they were making it much more useful for these like new mothers and stuff, to be prepared to have their child, because they advertised all these products to them that, like a lot of other new mothers would get, that they maybe wouldn't have expected to get before. So it's really helping the consumers and obviously, they want them to shop for the stuff at Target. They were giving them coupons and stuff, for the stuff that they would actually need.

Rupert mentions multiple times that Target is being helpful, stating that they are "making [shopping] much more useful" and that they are "really helping the consumer." Rupert also describes the relationship between Target and new mothers as one in which Target is giving to them. All these vocalizations construct Target as benevolent and helpful to pregnant women and new mothers.

In these same turns of talk, Rupert also makes statements that construct pregnant women and new mothers as unprepared and in need of help. His utterance that Target is helping new mothers "be prepared to have their child" simultaneously implies that without Target's interventions, these women would otherwise be unprepared. Rupert also describes Target as providing advertisements for products women might not otherwise get but still need. By describing pregnant women and new mothers as needing certain products, but framing their access to these products through Target, he constructs them as in need of Target's help. Rakesh reinforces these constructions in his next turn of talk. He states:

Rakesh: I mean, part of the article mentioned that some of the new mothers didn't even know that they needed certain things. It was only after they saw the advertisement from Target, that they were like "oh my gosh, okay maybe we should buy this too."

He describes how new mothers "didn't even know that they needed certain things". In this sentence, Rakesh's framing conveys a slightly different shade of meaning from Rupert's earlier construction of them as unprepared. His focus on pregnant women and new mothers as not knowing what they needed implies more than them being unprepared or in need of help, constructing them more closely as unknowledgeable or ignorant. This construction is also clear in his next sentence, when he states, "oh my gosh, okay maybe we should buy this too". In this sentence, Rakesh takes on the voice of a pregnant woman shopping at Target. His use of the phrase "oh my gosh" conveys a surprise at seeing the product Target is advertising, implying that the woman had not thought of the product before seeing Target's advertisement and supporting the construction of pregnant women and new mothers being unknowledgeable about products they need.

From this segment of transcript, we can see that these two constructions of Target as benevolent or helpful and pregnant women and new mothers as unprepared, unknowledgeable, and in need of help do not happen separately and instead mutually emerge entangled with each 


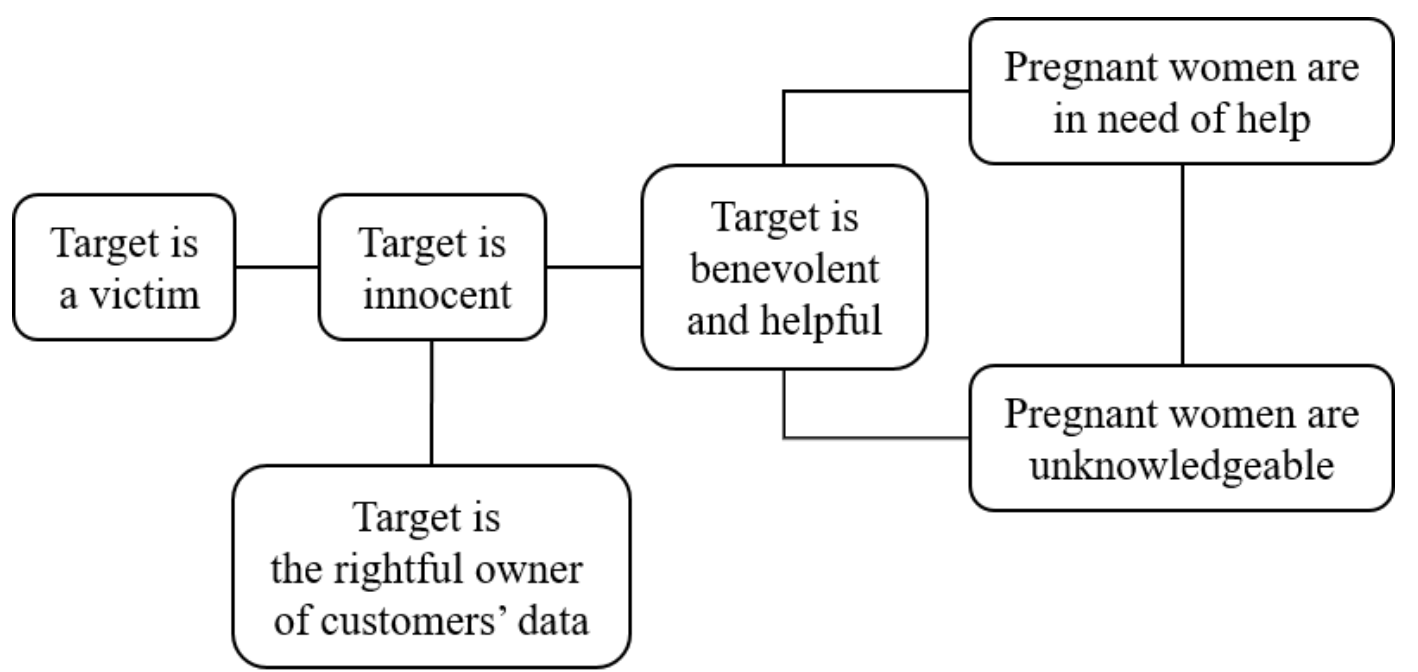

Figure 1: a schematic representation of the six major representations that have emerged in the conversation so far.

other. To demonstrate this entanglement, we reproduce Rupert's turn of talk below with additional coding for where he constructs Target (bold) and where he constructs pregnant women and new mothers (italics).

Rupert: I agree with you. I think they were making it much more useful for these like new mothers and stuff, to be prepared to have their child, because they advertised all these products to them that, like a lot of other new mothers would get, that they maybe wouldn't have expected to get before. So it's really helping the consumers and obviously, they want them to shop for the stuff at Target. They were giving them coupons and stuff, for the stuff that they would actually need.

This representation demonstrates how temporally close the two constructions are in dialogue, with statements that imply that pregnant women and new mothers are unprepared and in need of help occurring in the same phrase as constructions of Target as benevolent. These constructions interlace back and forth and follow a logical thread in which Target's beneficence necessitates pregnant women and new mothers as unprepared and in need of help. For example, in Rupert's statement that "[Target was] giving [new mothers] coupons and stuff, for the stuff that they would actually need", Target's beneficence in giving to new mothers relies on a logic in which new mothers have a need for Target's products.

From the analysis up to this point, six major constructions have emerged: Target as a victim, Target as innocent, Target as the rightful owner of customer's data, Target as benevolent, pregnant women and new mothers as needing Target's help, and pregnant women and new mothers as being unknowledgeable (Figure 1). The analysis has also shown how these constructions are strongly interconnected, either emerging mutually or entangled with previous constructions.

The way students relationally construct these stakeholders constrained the ways in which the students were able to understand any of them as causing harm or being harmed. Target's 
immediate construction as a victim and its subsequent entanglements with constructions of Target as innocent and Target as benevolent and helpful constrain the ways that Target's collection and use of customer's data is perceived as potentially harmful. Once Target is collectively constructed as innocent and justified in its data collection and targeted advertising to customers, these practices are no longer thought of as potentially harmful practices. This is evident in the next turn of talk, when Bill introduces into the conversation what made him uncomfortable about Target's practices. Bill states:

Bill: I agree with you, on like taking data on who shops at your store. You're choosing to shop there, it is their store, they can take data. I think where things got like a little shady and a little bit on like personal, when I read that I was like hmm, that doesn't seem exactly onboard, is where, in the coupons, they realized that like women who are pregnant, getting a bunch of pregnant item coupons in the mail was like freaking some of them out, and so then they hid the coupons next to like regular things. .... Yeah, and I think that that's kind of where it got like a littleat that point it becomes a little bit more manipulative, because you're expressly trying to get it so that they don't know what you're doing, and I think that's where things get a little bit less clear-cut, like right or wrong. Because I agree, you take data, it's your store, that's your prerogative. Even coming up with a statistical tool to figure out who is pregnant and who is not, that's just a tool. You can't really blame the statistician. I think where it gets weird is where they don't want you to know that they know.

Two important points emerge from Bill's statements. First, that Bill is uncomfortable with a certain aspect of Target's practices, that they are hiding that they know that women are pregnant. Bill describes these practices as "shady," "manipulative," and "weird," all of which express discomfort and construct these practices as potentially unethical. Second, though Bill constructs Target as manipulative, he still vocalizes agreement with Rakesh's earlier statement constructing Target as innocent. Because Target is constructed as innocent in its collection of data and advertising, Target's behavior is viewed as potentially harmful in very limited ways. Target is only capable of causing harm based on its intentional efforts to manipulate pregnant women, not necessarily because they are collecting pregnant women's data and advertising to them.

Target's construction as benevolent also constrains how pregnant women and new mothers are perceived as being harmed, resulting in harm against pregnant women in the case study to be largely minimized. Because Target's construction as benevolent and helpful is entangled with pregnant women and new mothers' construction as in need of help, the major relationship that emerges in conversation between the two is one in which Target is helping pregnant women, and this relationship obscures students' ability to see Target as causing pregnant women and new mothers harm. Evidence that these constructions constrain pregnant women to only be perceived as benefited by Target can be seen in the next part of the transcript, when Zafar states:

Zafar: You know when I read it, I had the same feeling. I said okay, they just use the science to just increase their profit, but I asked myself why I'm feeling bad. When I finished it, I had like a negative feeling inside, and I think it was this tool by itself is not the bad thing. They used science, they used statistics to just increase the profits, but I think at some level, I was afraid at how far this can go. For now 
it's just okay, my wife is pregnant, they provide me with something I need, that's good, but if that - how far it can go. This, I think for me, that was the scary part. For now, everything is okay, I need something, they offer me it, that's it, but if it can get so deep into my life, what else?

In this turn of talk, Zafar responds to Bill and describes how he also felt uncomfortable with Target's practices. Like Bill, Zafar reiterates that Target is innocent. However, where Bill identifies his discomfort as stemming from Target's specific manipulative actions, Zafar instead locates his discomfort as a bad or negative feeling stemming from the possibility that this technology could be invasive and interfere with his life.

At the same time as he expresses his discomfort with Target's ability to interfere with people's lives, he describes the relationship between Target and pregnant women in the case study without this same discomfort. He states, "For now it's just okay, my wife is pregnant, they provide me with something I need, that's good...." Here, Zafar's description of Target as "providing me with something I need" recalls the entangled construction of Target as benevolent and pregnant women as in need of help. Zafar's statement invokes these constructions to make an exception for pregnant women to his statement about Target interfering with people's lives; because pregnant women are actually being helped by Target, they are not among the people for whom Target is harming by going too far and interfering with their lives. As a result, even while Zafar describes people as being potentially harmed by predictive analytics because of its invasiveness, the collective construction of Target as benevolent and helpful and pregnant women as in need of help constrains pregnant women and new mothers to not being harmed and only being helped by Target.

\section{Segment 2}

Segment 2 of our data encompasses minutes 3-27 of the third focus group session. We showed above how in segment 1 , the students did not conceptualize pregnant women and new mothers as being harmed or even vulnerable to harm and did not consider predictive analytics as capable of causing meaningful harm to pregnant woman. In response, Ayush and Dan began the third session by taking a step back from the particular case of Target advertising to pregnant women and new mothers and focusing on predictive advertising more generally. They started the session with a story-telling activity targeted at providing the students opportunities to consider other circumstances in which companies could use predictive analytical advertising and to imagine how a person could be harmed by it. Because this segment is not focused specifically on the case of Target advertising to pregnant women and new mothers, we are not spending as much time presenting an analysis of how stakeholders are constructed. Instead, we want to draw attention to how, as a result of this new context, there is a shift in how students conceptualize predictive analytics, and students begin to show the seeds of conceptualizing possible harms cascading from aggressive predictive advertising.

After giving a brief overview of the day, Ayush prompts the students to spend some time considering how someone they know could be theoretically impacted or harmed by a company using predictive analytics to advertise to them. Ayush then breaks the students into two groups of three students each to discuss possible narratives of how people could be impacted. Ayush facilitates the group containing Rakesh, Zafar, and Bill; and Dan facilitates the group containing Feng, John, and Rupert. Kwan is absent from this session. 
During Dan's small group discussion, Rupert describes a scenario where someone with depression or an eating disorder is advertised to and is unable to control their purchases. John adds on to Rupert's description and points out and specifically identifies how companies are taking advantage of people's vulnerability. Later in the conversation, Rupert brings up another example of a person with a shopping addiction. He states, "another thing I thought was like shopping addiction. People have shopping addictions, it's like they—it like exploits those people. And like I guess these online marketers like kind of look for people with.... [interrupted]" Rupert's description of predictive analytics as exploiting and his description of online marketers as looking for people with addictions frames both frame companies as predatory. The student's descriptions of companies during this segment starkly contrast their earlier conversations in segment 1 , where students did not vocalize the subjects of predictive analytical marketing as being vulnerable or potentially harmed, and continually described Target's use of predictive analytics as innocent and helpful. An important detail about how students conceptualize harm by predictive analytics here is that they rely on the advertiser being specifically, intentionally exploitative thereby implicitly framing predictive analytics as ethically neutral. A similar shift is seen in the other small group.

In Ayush's small group, the students discuss a single scenario more deeply, bringing out several different ways a person can be multiply impacted. Bill first brings up the scenario of how someone with an addiction trying to kick a habit would be vulnerable to predictive analytics. He goes on to describe how someone with a smoking addiction might not want their family to know about their addiction and might be trying to hide it. Subsequently, Zafar and Rakesh build upon Bill's description. Rakesh draws a parallel between Bill's scenario and the circumstances of pregnant women from the previous day, and Zafar describes how predictive analytics would make it more difficult for someone to hide being a smoker. Bill adds to this, describing how it might prevent the person from changing their addiction. He adds that the person's family could find out, and that if the company went as far as to send free samples, the person could even relapse. Zafar and Bill go on to describe how would be financially affected, and Zafar describes how aggressive advertising using predictive analytics would even affect your ability to feel safe.

Towards the end of the segment, Bill summarizes several of the different ways a company's aggressive advertising using predictive analytics cascaded to impact a person. He states:

Bill: $\quad$ So this guy—so this guy is financially affected, he's losing money, he relapses. His family and friends find out. Which, yeah, a mental toll, as well as the mental feeling of unsafeness and security, um, that his privacy's violated. And then like-and then he's stuck. He's stuck-for like what could he do? I mean, there's really not too much he could do because, yeah, you can't avoid it.

Bill identifies several of the immediate material consequences of being targeted with predictive analytics and aggressive advertising such as being financially affected and relapsing, and also identifies less immediate consequences such as how it might take a mental toll, feelings of lacking safety and having your privacy violated, and not having any options in a way that relates hopelessness.

In segment 2, we see a significant shift in how students are conceptualizing stakeholders. Where in segment 1 , we saw strong constructions emerge of Target as both innocent and 
benevolent as a company utilizing predictive analytics to aggressively market to pregnant women, in this segment, there is a weakening of these constructions as students conceptualize multiple ways that the targets of aggressive predictive analytical advertising may be harmed. These conceptualizations act as important resources that students draw upon in subsequent segments where students return to discussing the Target case.

\section{Segment 3}

Segment 3 of our data consists of 13 minutes of conversation beginning 30 minutes into session four. Before session four, students were assigned to read an article by Weick (1990) analyzing the case of the Tenerife air disaster (in which two planes collided leading to a loss of hundreds of lives) from a systems perspective. The author presents how a stressful situation, in part created by weather events, can quickly lead to erosion of otherwise sound cognitive and communication efficiencies, leading to a multiplication of errors that ultimately culminated in the disaster. The students begin session four by discussing the Tenerife case. About 20 minutes into the discussion, Feng invites the group to reflect on how the issues being considered in the Tenerife case are similar or not to the Target case. This brings Target back into the group's collective focus. Multiple participants express concern that it wasn't at all obvious or clear what the connections between the two cases were, even expressing skepticism about whether there were any meaningful connections at all. The participants explore possible cross-case connections and in the process construct Target and customers in new ways.

We limit extensive micro-genetic analyses of the constructions from this portion of conversation since the pregnant woman had largely faded from the group's attention. Importantly, however, participants do productively use the Tenerife case as a conceptual analog for thinking about Target, which supports participants in seeing Target as intentionally stressing their customers out, in hopes that their customers will make a mistake and buy things that they don't normally buy and don't need.

The segment begins 30 minutes into session four. Bill repeats back and synthesizes what he hears as the perspective emerging from the group about the relationship between the Tenerife case and the Target case. In the process he describes Target as analogous to the clouds in the Tenerife case, conceptualizing Target as diffusely contributing to creating stress. This creation of stress is conceptualized as a factor that contributes to a customer making a poor decision that might have negative effects.

Bill: Target is the cloud causing stress.... you have a stressor causing someone to make a poor decision, which might have negative effects. So, like, you have Target causing stress on a customer, who might end up, like, buying from Target for the rest of their life, regardless of whether or not that's, like, good, bad, or whatever.

As the conversation continues, Feng elaborates that Target is creating stress not just for the customers, but also potentially for the engineer/statistician/data analyst.

Feng: The people who, the engineer who do data... analysis. They may also have similar, they may also have the similar condition, like, the shop give them a lot of stress, says, 'Okay, you need to help us to make more money. We need more 
profits or I won't pay you for this design. ...you won't get money from me.' So they are also under pressure.

Here Feng constructs Target as motivated by making more money and using this demand for more profits to coerce their employees into developing particular designs (and threatening to withhold pay if the employee doesn't follow through with their demands).

In this excerpt of dialogue, there are some dominant constructions of Target, customers, and engineers that unfold, as well as some connections/relationships between actors that take shape. Target is constructed as a diffuse stresser. In this way, they are seen as contributing to the stress customers experience which makes these customers more likely to make poor decisions. Target is also constructed as contributing to stressing its employees such as engineers or data analysts that might work for Target. Target is also constructed as profit hungry and coercive while engineers are constructed as dependent on Target for money. These constructions are represented schematically in Figure 2 below. Importantly, these constructions of Target put Target in a more negative light than in previous sessions.

Approximately 30 minutes into this session, Ayush and Dan bid to shift the focus of the discussion to the potential consequences for the pregnant woman and her family from the Target case study. Dan invites the group to take some time to "to think about the girl who had her pregnancy outed because of all this predictive analytic stuff. ...What's actually gonna happen to her, or to her family? We just want to think about some potential scenarios ... what kinds of consequences could this have for the girl? ...What maybe happens?" Feng bids to ask a question before other participants answer. Feng asks:

Feng: Are we supposed to do, be influenced by something we buy from the store? It's like, this girl, buys something in the supermarket and it's in there, it's in her advertisement and change her life. Maybe positive, maybe negative, but a whole family, her family, was impacted. Okay? But, are we supposed to, be impacted in this way? Because if we just want to buy things, we just want to use these things. They is not supposed to influence my life.

Here Feng does some interesting shifts to begin projecting himself into these scenes and not being personally comfortable with Target getting this involved in his life. Feng continues projecting himself into this scenario:

Feng: I just want to shop here. I don't want any other things. ...I go to Target. The purpose I bought the stuff because I, you, need to use this stuff. The purpose I went into Target is because I need to buy things. That's it. You don't have any other things to do with Target. I don't want you to otherwise to my life. I don't want you to do, you know, any suggestions to my father. It's different, yeah.

In the process of positioning himself within the scenario, Feng also constructs Target in new ways. Target is described as not being supposed to have so much influence and impact in someone's life. In this way Target is conceptualized as invasive, as getting overly involved in places they shouldn't be. Feng sees himself as a customer going into Target simply to purchase things that he needs, and as not inviting Target into his life in any additional ways and as definitely not wanting Target to disclosing his shopping habits to his father. These constructions 


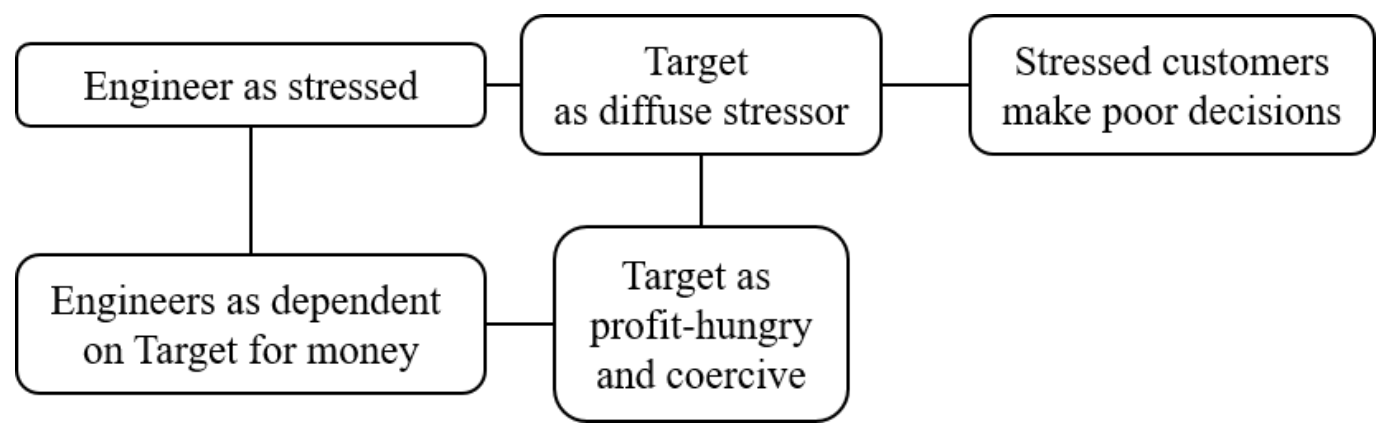

Figure 2: This figure illustrates some of the local stabilities in how Target is being conceptualized as the group draws analogies across two case studies. In these conceptualizations, Target is put in a more negative light than in conversations in previous days.

begin to construct Target as invasive and customers (such as Feng and the pregnant woman) as potentially harmed by Target's invasiveness. These relationships are represented in Figure 3, within the bolded rectangle. For our current analytical purposes, we foreground constructions of the pregnant woman and background how Feng as a customer is constructed here though we acknowledge that this projection of self into the scenario might be doing important work to shift the constructions of Target that are available.

Following Feng's multiple turns of talk, Dan and Ayush re-introduce the discussion prompt about what could possibly happens to the girl and her family. Over the 4-5 minutes of discussion that follows, participants seem to sustain an attention to Target as invasive and the girl as potentially harmed (as represented in the bold box in Figure 3) and begin to flesh out more specific consequences that could unfold for the pregnant woman and her family as a result. As represented schematically below, the participants elaborate multiple ways in which the pregnant woman's life could be impacted. Most of the ways they describe involve harm, and one is construed as potentially positive for the woman (see Figure 3 below). In the process, participants begin to elaborate on other actors that are impacted by these events such as the baby's father and the pregnant woman's family. Two examples of harm get particular traction within the group. The first of these is how disclosing the woman's pregnancy could disrupt the woman's relationship with the baby's father, as evidenced by Bill's statement: "So that brings up trust issues, which should also stem between her and whoever the father is, 'Oh, like, why didn't you tell me? Why isn't that the first thing?"' Another significant example of harm that the students express is how disclosure would create stress and trust issues between the woman and her parents, which can be seen in another of Bill's statements: "One that I just thought of directly stemming from the fact that she was outed by Target is trust issues. That's the biggest thing - that I can think of is, like, she didn't tell the family. The family found out through Target. So, therefore that brings up, "Why didn't you tell us?" Additional supporting evidence for the consequences summarized in Figure 3 can be found in the Appendix. 


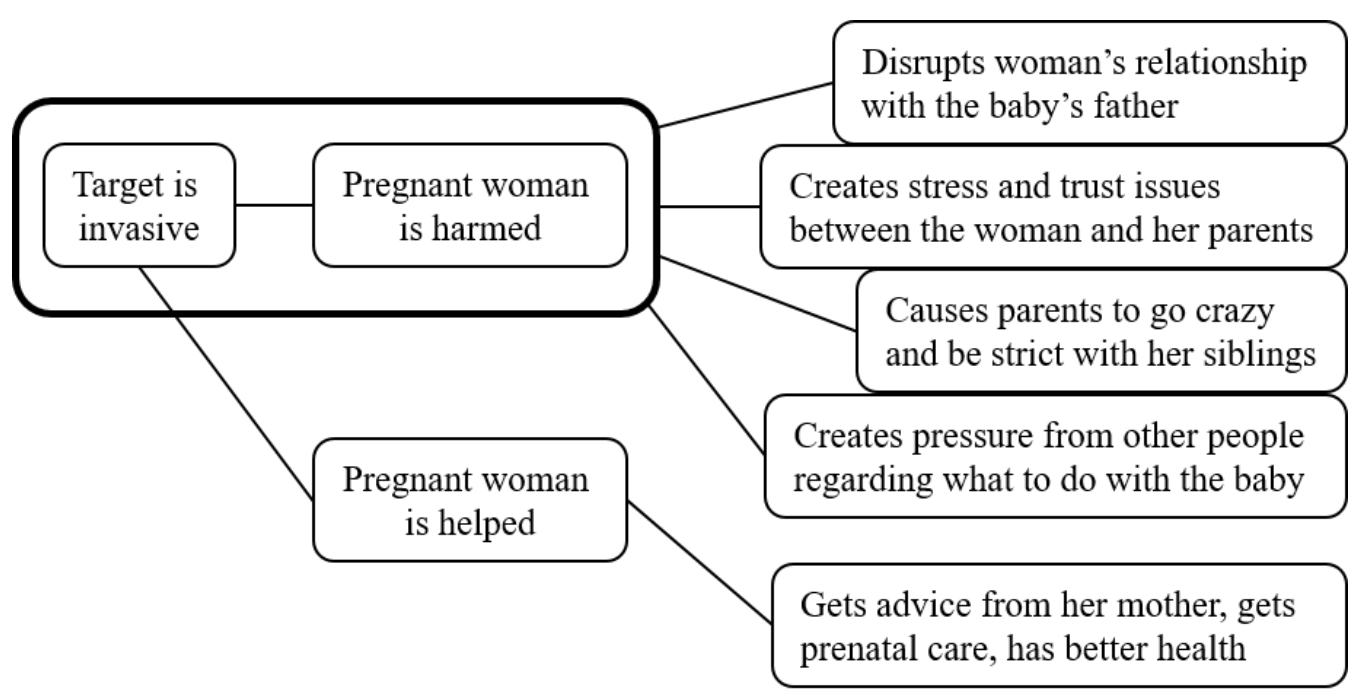

Figure 3: This figure illustrates the local stabilities in how Target and the pregnant woman are being conceptualized. The stacked rectangles on the right display the specific consequences for the pregnant woman that the participants verbalized which elaborate the potential harm done.

In Segment 3, the participants fleshed out specific plausible consequences for the pregnant woman and at the same time, elaborated on the positionings of the stakeholders such as Target and the pregnant woman. We see the participants elaborating the causality of harm and giving the harm a more specific form. These stabilities seem to rely on some earlier assumptions from Figure 2 that built the positions of Target as invasive and as capable of causing harm. In this segment, we see participants elaborating and detailing harm to the pregnant woman caused by Target in ways that were strongly missing in earlier sessions.

\section{Segment 4}

The fourth and final segment that we present in this paper is continuous with segment 3 and encompasses minutes 47-60 of the fourth focus group session. During this segment, the participants start articulating more actors who might have influenced the harmful consequences students discussed in segment 3 . As such, Target's actions gradually come to be seen as one component of a compounding set of events. Entangled with this, we see that at different times the participants adopt different stances whether the nature of the harm is a result of Target's advertising or instead linked to the very nature of being pregnant. These lead participants to adopt varying stances towards how causal a role Target's actions played in constructing the harm, arguing at times the centrality of Target's role, and at other times, constructing Target as innocent and having little responsibility towards an event that was inevitable.

In the first few minutes of this segment, the conversation centered around the woman's pregnancy. The articles on the Target case that we shared with the participants did contain many details on the specific context surrounding the woman's life, and the participants often engaged in speculation in this section. Specifically, students speculated on the dynamics of how the woman's pregnancy was disclosed and whether and how one might want to hide it or disclose it. Notions of how society conceptualizes teenage pregnancy were sometimes tacit and sometimes explicit in participants' responses. 
In his first utterance, Bill shares a list of different ways that the teenage pregnant woman might be thinking about the pregnancy.

Bill: $\quad$...she could be "indecisive about her decision on what she wants to do with the child. She might - - like, be considering, like adoption - - or, you know, other routes, Um, maybe she's ashamed. That could be it. Maybe she's scared.

Feng: Or maybe she just looking for an opportunity like that.

Bill: Maybe she's like, planning a surprise, like, maybe she's planning a surprise, like, "I'm pregnant!" And then, stupid Target ruins it."

In this excerpt, student constructions of the woman as possibly ashamed, scared, indecisive, or celebrating her pregnancy emerge in conjunction with Target as a spoilsport that takes away that decision-making opportunity from her.

Rakesh responds by introducing society's reactions to teenage pregnancy, that the woman and her family might have to face social stigma. Bill builds on that, noting that a child out of wedlock is still a taboo in certain places. This, however, leads to Rakesh and Bill reasoning in ways that distances Target from the specific harm to the woman. Rakesh notes, "even if it were not for Target, it could be someone else from society telling that to her parents ... but it's just that this time that the Target was play the spoilsport." Bill follows Rakesh's statement,

Bill: I feel like a lot of the consequences are just consequences of having a child out of, like, in a situation where, like, they're hiding it versus, like, having Target out them. You know what I'm saying, like, society looking down on her isn't, I don't think, a consequence - of Target. I don't think Target being the ones to out her is the reason people would be upset.

Here, society's attitudes towards teenage pregnancy start functioning to distance Target from the event of disclosing the woman's pregnancy to her family, contributing to construction of Target as innocent at best, or a spoilsport at worst (a role that many other actors likely could have played). In this latter stance (that many other people could have played the spoilsport), we note how the 'outing' of the woman's pregnancy to her family starts getting constructed as an inevitability; this gains further traction as the statement continues, and it contributes to strengthening the positioning of Target as innocent.

Thinking about whether the harm that precipitates from the activities of Target was inevitable, Bill takes the view that Target can't be held accountable. He analogizes to situations where an innocuous action can lead to a subsequent disaster, drawing on the metaphor of the "butterfly effect." He elaborates:

Bill: I don't think Target can, like, take responsibility for that because, yeah, it's like a sensitive subject, but at the same time, I think it is somewhat like ... It could have been, it, if it wasn't Target, like, what if her parents found a pregnancy test in the trash can? Like, there could, there's a hundred different things that could set off that chain of events, and like, I guess, Target specifically, it's just because this is specifically targeted towards pregnant women, that does bring up this issue. And it does, like, have a higher propensity. But, I don't think the probability of 
something like this happening, um, should prevent Target, like, I don't think they should be, like, "Oh, there's a, a one in a million chance that this ruins someone's life. Like, we can't do that."

Zafar: But what if it happens?

Bill: $\quad$ But if it happens, then they call it an accident because it's an accident.

Here, Target as well as the woman are embedded tacitly in a complex web of actions and any harm that accrues to the woman is framed as an "accident." We also note the contradiction in how the disclosure of pregnancy is treated at one point as an inevitability (in that it could result from a "hundred different" initiating events), while the harm resulting from the disclosure is constructed as a highly improbable event.

Integrating across this first portion of Segment 4, we see how the introduction of "society" as the actor stigmatizing teenage or unmarried pregnancy as well as the introduction of many possible actors who could possibly initiate a chain of events leading to the eventual disclosure of the woman's pregnancy serve to distance Target's role in that disclosure and its effects and position Target as innocent with the disclosure as an accident. Here too the constructions of the stakeholders are entangled. The positioning of woman as keeping her pregnancy secret (for a variety of speculated reasons) is necessary for positioning Target as a revealer of that secret, and the subsequent positioning of Target as innocent is contingent upon the simultaneous positioning of the specific woman in the case study (and her context) as

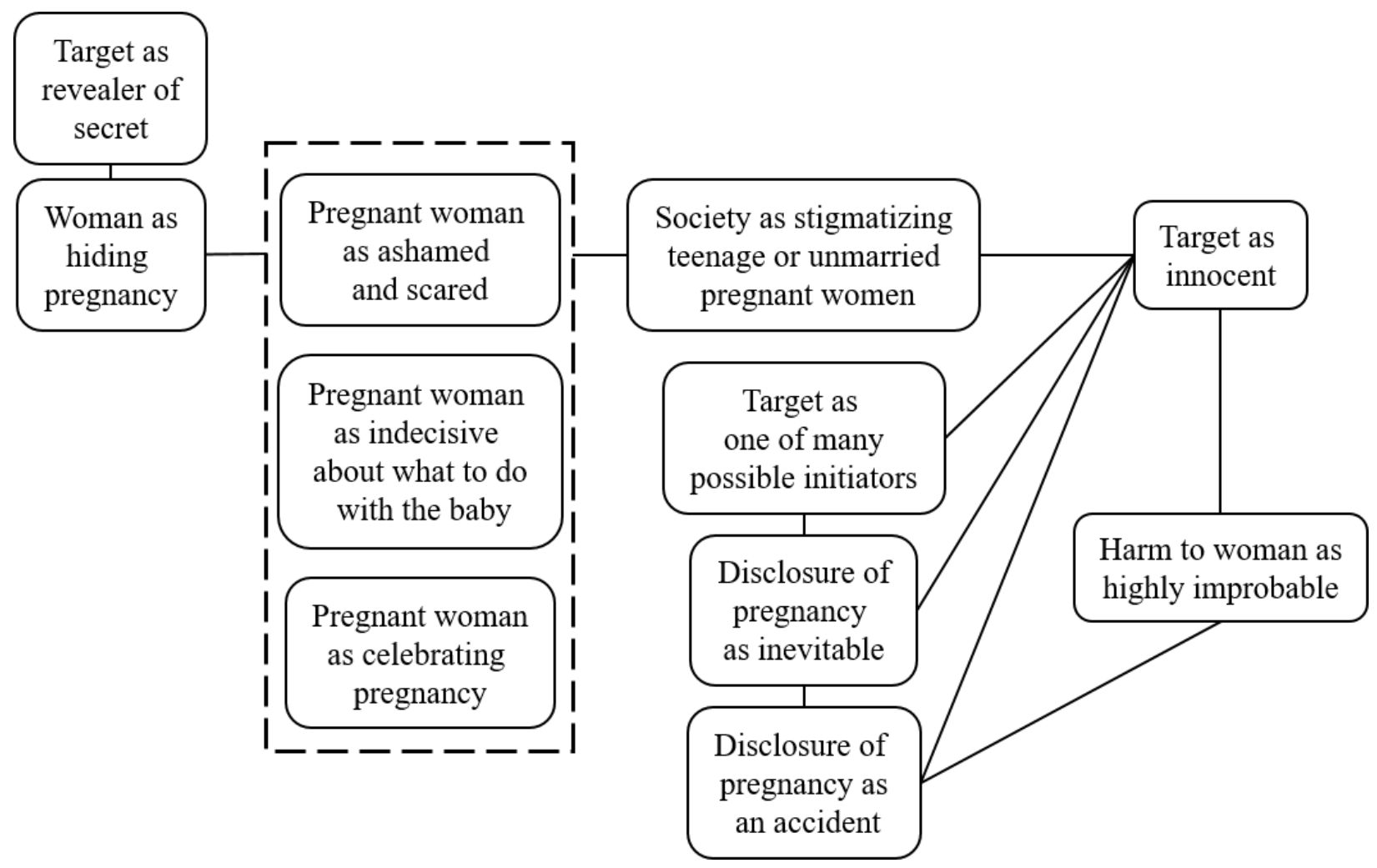

Figure 4: The entangled constructions of Target and the pregnant woman in the first part of Segment 4. 
improbable and an accident. We also note that as the participants start considering a complex causality for the entire event, it diffuses the connection between the technology production and its social ramifications. These constructions that appear in Segment 4 so far are shown in Figure 4.

In this segment, not all participants had concurrent congruent evaluations of the situation. Zafar and Feng, for example, had a different reaction. While they elaborate less, they take the position that Target's intervention was the crucial bit that led to the events ultimately harming the woman. In response to Bill's comment that Target should not have to consider such an improbable event, Feng draws up an analogy with a medical drug trial in which it would be really important to consider harmful side effects to even a few patients, even in the case of a drug that is otherwise aiming to treat a fatal disease. Zafar agrees, and elaborates that in the case of Target it's not even about helping people, it's driven by profit: "But it's even worse in Target case because there's no holy reason behind it. It's just making more money." In response, Bill shifts his position a bit, acknowledging profit as the sole motive. His language imagines Target's advertisements as "hooks," positioning Target as a fisher-person and customers as fish; a predator-prey relationship. While "smart" customers could potentially make use of the coupons while avoiding the negative impact, he notes that it's "dangerous, because the hook's always there."

The constructions that emerge in this latter part of Segment 4 are shown in Figure 5. Notice how the constructions here contrast those from the previous part of Segment 4.

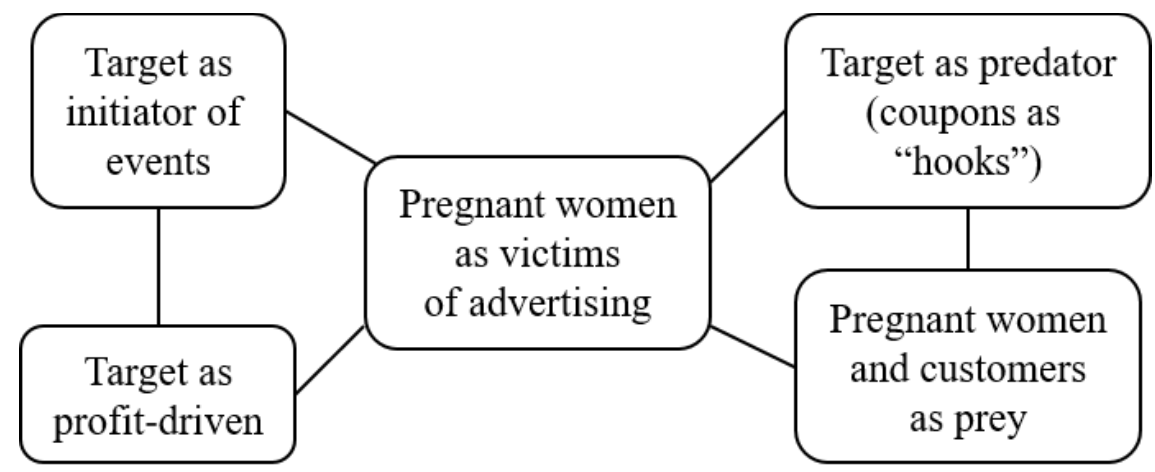

Figure 5: Showing alternative constructions of Target and women that also took place in segment 4.

We stop here in our analysis for two reasons. First, the subsequent discussion turned to the themes of legality versus morality, codes of ethics, and how to assign responsibility for the unfolding events; and second, we feel that these segments, so far, give us enough empirical traction to illustrate our claims focused on conceptualization of harm and entangled constructions of the stakeholders.

\section{Discussion}

We have presented our analysis of participants' (engineering senior and graduate students) conversations spanning three focus group sessions. We want to turn now from analyzing transcript to discussing what these results mean for researchers and instructors. 
We've demonstrated through this analysis that the various ways students construct Target and pregnant women and new mothers are entangled with each other, forming a complicated network, and we have discussed in-depth some of the constructions that emerged. Second, we've shown how the ways students perceive stakeholders as being harmed or capable of harm is strongly connected to these moment-to-moment stakeholder constructions, and as a result, the way the pregnant woman was harmed in the case study was often minimized. In the first session, harm was either unacknowledged or positioned simply as an innocuous violation of privacy. It is only in their third session discussing the Target case study that students engage with more sophisticated notions of harm and begin to consider how the pregnant woman was harmed by the products of engineering design. In typical engineering ethics classrooms, where 30-60 minutes are reserved for case study discussions, conversations might be terminated at points where students haven't had the chance to grapple with the implications for various stakeholders. It might also require significantly more scaffolding to condense the discussions that spanned six hours into a much shorter timeframe. We fear that such scaffolding might compromise more open-ended discussions where students refine their own understanding through dialog, leading to more convergent rather than divergent thinking. As Haws (2001) notes, there is a need in ethics curricula to engender more divergent thinking, helping our students to see the broader ramifications of the work of engineering beyond a narrow technical focus. As a result, one of the major takeaways of this analysis is that the amount of time it takes students to engage deeply in sociotechnical case studies is significant, and if engineering ethics instructors want their students to engage with these case studies in meaningful ways, instructors need to build into their curriculum time for students to work on a single case study for more than a single week of class.

The constructions of stakeholders that emerged often drew on assumptions codified in the language of engineering codes of ethics. Language in codes of ethics, such as engineers should work for the "advancement of the society, health, and well-being of their community" (National Society of Professional Engineers, 2007) already frame engineering as always benevolent and helpful. This framing is problematic because it presumes that engineering as a discipline and engineers as individuals are aware of what the people they impact need, when this is not always the case. In our data, these same assumptions about engineering manifested quickly, and contributed to the resistance to seriously considering the harm to pregnant woman and new mothers and of the framing of Target - and its engineers and statisticians - as benevolent. In light of this, we feel that engineering ethics instructors need to ensure their students are not taking codes of ethics for granted, and they need to create educational spaces in which students are required to critically engage with what codes of ethics mean and how they might fail to do the work they set out to (Haws, 2001).

Some of our work connects to Riley's review of how feminist ethics can be used to challenge masculinist approaches to ethics that tend to universalize, depersonalize, and abstract (Riley, 2011). Such masculinist ethics results in dismissing relationships and under-emphasizing social and political contexts. Within feminist ethics perspectives, a focus on emphasizing relationships between people, constructing narratives to provide context, and communicating strongly aligns with what we believe enabled the students to consider deeply who was vulnerable and who was harmed in the Target case study. Additionally, feminist ethicists have theorized how identity constrains people's agency as moral actors, and we suspect that engineering as an identity contributed to what moral considerations were easily available to the students during their discussions. 
The participants in these focus group discussions (including the facilitators) all identified as men. We speculate that this too contributed to the difficulty in identifying the needs of a pregnant woman and empathizing with how predictive analytics had potentially harmed her. We want to be clear that this analysis is not pointing out deficiencies in the students. This speaks instead to how difficult it is for students to take perspectives across lines of gender (and potentially other identities such as race and socioeconomic differences (Gupta, Elby, Turpen, \& Philip, 2016)) especially when students of certain identities and backgrounds are absent from the conversation. Power can often be a barrier to perspective-taking (Galinsky et. al., 2006). We speculate whether the challenges to getting students to attend to "structural violence" (Galtung \& Höivik, 1971), as documented by Lachney and Banks (2017), are related to the challenges in perspective-taking across lines of power and privilege. Because "structural violence" disproportionately marginalizes non-dominant members of a community or society (Galtung, 1990), it becomes more important to be able to think expansively about the impact of engineering and technology to include structural harm. Additionally, since engineers often belong to dominant communities (Slaton, 2010, 2015), Galinsky's work (2006) suggests it would take more scaffolding to help them take perspectives of non-dominant stakeholders in the context of a specific technology use. As a result, instructors must create classrooms where students have both the time and resources to engage with a diversity of perspectives. While some efforts in engineering education have started exploring ways in which to scaffold perspective-taking in the context of ethics and of engineering design (Jaycox et. al. 2014; Hess, Strobel, \& Brightman, 2017), we need to further develop research-based instructional strategies to help equip our students with the tools for perspective-taking.

How participants constructed stakeholders and conceptualized harm was influenced by how facilitators framed class discussion and attended to these constructions as they manifested. For example, the facilitators were taken aback at how in the second session participants did not conceptualize any meaningful harm to pregnant women, which led them to revise their subsequent plan. Speculating that perhaps the context of pregnancy is difficult for the participants to fully empathize with, they decided to ask participants to imagine other scenarios where people might be harmed from advertising based on predictive analytics. Instructors also specifically conceptualized different ways in which the pregnant woman in the case-study could experience harm. Besides these pre-planned prompts and facilitation moves, facilitators' in-themoment actions also guided the conversation, serving to create or take-away space for building on or fleshing out certain constructions of stakeholders. Considering how facilitators attend or fail to attend to these constructions as they emerge in conversation is significant in developing a more complete picture of student reasoning. While we do not attend specifically to facilitator moves in this analysis, we hope to pursue that in future.

We also want to highlight the very contextual nature of participants' reasoning in the data. Often the manner in which participants reacted or how they positioned the stakeholders (Target and pregnant women and new mothers), or conceptualized harm was embedded in the very local lines of reasoning and analogies. For example, when thinking about how society stigmatizes pregnant teenagers, Bill distanced Target from harm caused to the pregnant teenager by disclosing her pregnancy. Minutes later, in responding to the analogy of the medical drug trial, Bill positions Target as a predator with the coupons as "dangerous" hooks. Our point here is that students' reasoning (and cognition) about sociotechnical issues are highly sensitive to context, and dynamic rather than stable or belief-like. This observation is aligned with a fairly 
large body of work arguing for the context-sensitive nature of learners' cognition, developed mostly in the context of disciplinary reasoning (Smith, diSessa, \& Roschelle, 1994; Hammer \& Elby, 2002; Gupta, Hammer, \& Redish, 2010; Gupta \& Elby, 2011; diSessa, 2017). There is a need in engineering ethics education research to understand and unpack these dynamics and patterns of students' reasoning about sociotechnical issues (Philip, Gupta, Elby, \& Turpen, 2017). Such understanding can contribute towards fundamental research on the nature of ethical reasoning as well as towards careful design of instructional prompts.

Methodologies for doing fine-grained analysis of student perspectives as presented in this paper provide an opportunity for unpacking how students reason about engineering stakeholders and how broader constructs such as which stakeholders students see as being harmed come to be in moment-to-moment interactions among students. This paper hopes to contribute to scholarship that helps researchers in engineering ethics develop more detailed analytical tools.

\section{Acknowledgments}

We thank the participants who volunteered for our research study. We thank Thomas Philip, Andrew Elby, and Daniel Dilliplane for participating in the design of prompts for focus group sessions, and Daniel Dilliplane for also co-facilitating the sessions with Gupta. This material is based upon work supported by the National Science Foundation under Grant No. SES \#1338700 and SES \#1338753. Any opinions, findings, and conclusions or recommendations expressed in this material are those of the author(s) and do not necessarily reflect the views of the National Science Foundation. 


\section{Appendix}

\begin{tabular}{|c|c|}
\hline Consequence Imagined & Evidence from Transcript (Segment 3) \\
\hline $\begin{array}{l}\text { Disrupts woman's } \\
\text { relationship with the } \\
\text { baby's father }\end{array}$ & $\begin{array}{l}\text { Bill: [It could] "influence the relationship between her and } \\
\text { whoever the baby's father is, and that's like step one. The family's } \\
\text { gonna be like, "Who's the dad?" I guess. And then, there could be } \\
\text { a whole host of issues from that. ...the relationship between her } \\
\text { and the guy" } \\
\text { Feng: "And just the relation between her and her boyfriend, } \\
\text { actually, and, maybe stress." } \\
\text { Bill: "So that brings up trust issues, which should also stem } \\
\text { between her and whoever the father is, "Oh, like, why didn't you } \\
\text { tell me? Why isn't that the first thing?" }\end{array}$ \\
\hline $\begin{array}{l}\text { Creates stress and trust } \\
\text { issues between woman \& } \\
\text { her parents }\end{array}$ & $\begin{array}{l}\text { Rakesh: "But you're talking about stress, there could be stress } \\
\text { between the first family, the girl, the guy, and maybe the guy's } \\
\text { family" } \\
\text { Feng: "The negative being stress, like, relations between family } \\
\text { relations. Her parents would be, maybe, very angry." } \\
\text { Bill: "One that I just thought of directly stemming from the fact } \\
\text { that she was outed by Target is trust issues. That's the biggest thing } \\
\text { - - that I can think of is, like, she didn't tell the family. The family } \\
\text { found out through Target. So, therefore that brings up, 'Why didn't } \\
\text { you tell us?" } \\
\text { Bill: "I'm sure she was waiting for the right moment - and now } \\
\text { they [the girl's family] just know." }\end{array}$ \\
\hline $\begin{array}{l}\text { Causes parent to go crazy } \\
\& \text { be strict with other } \\
\text { siblings }\end{array}$ & $\begin{array}{l}\text { Zafar: "We just don't know how the parents will act, like - the dad } \\
\text { may become crazy after this - act very seriously about the other } \\
\text { kids - like, there would be another sister in the home, another } \\
\text { brother." }\end{array}$ \\
\hline $\begin{array}{l}\text { Creates pressure from } \\
\text { other people regarding } \\
\text { what to do with the baby }\end{array}$ & $\begin{array}{l}\text { Bill: "maybe it's because she herself still wants time to decide } \\
\text { without people trying to convince her one way or the other." }\end{array}$ \\
\hline $\begin{array}{l}\text { Gets advice from her } \\
\text { mother or father, get } \\
\text { prenatal care, has better } \\
\text { health }\end{array}$ & $\begin{array}{l}\text { Feng: "So I think there's basically two kind of things positive in } \\
\text { fact. Her family knows she's pregnant, so her mother may give her } \\
\text { some advice to prevent something, 'cause her mother knows what } \\
\text { pregnancy will be like. So maybe, it's better to her, for her health." } \\
\text { Bill: "She can get the medical care that she needs. Prenatal care - } \\
\text { is important for a healthy child.." } \\
\text { Zafar: "...he [the girl's dad] may be, like, very understanding and } \\
\text { helpful dad, making with the health scan..." }\end{array}$ \\
\hline
\end{tabular}




\section{References}

Campbell, R. C., \& Wilson, D. (2017). Engineers' Responsibilities for Global Electronic Waste: Exploring Engineering Student Writing Through a Care Ethics Lens. Science and Engineering Ethics, 23(2), 591-622. https://doi.org/10.1007/s11948-016-9781-2

Code of Ethics | National Society of Professional Engineers. (n.d.). Retrieved December 31, 2017, from https://www.nspe.org/resources/ethics/code-ethics

DiSessa, A. A. (2017). Conceptual Change in a Microcosm: Comparative Learning Analysis of a Learning Event. Human Development, 60(1), 1-37.

Duhigg, C. (2012, February 16). How Companies Learn Your Secrets. The New York Times. Retrieved from https://www.nytimes.com/2012/02/19/magazine/shopping-habits.html

Engle, R. A., Conant, F. R., \& Greeno, J. G. (2007). Progressive refinement of hypotheses in videosupported research. Video Research in the Learning Sciences, 239-254.

Cech., E. A. (2014). Culture of Disengagement in Engineering Education? Science, Technology, \& Human Values, 39(1), 42-72. https://doi.org/10.1177/0162243913504305

Galinsky, A. D., Magee, J. C., Ena Inesi, M., \& Gruenfeld, D. H., (2006). Power and Perspectives Not Taken. Psychological Science, 17(12), 1068 - 1074. https://doi.org/10.1111/j.14679280.2006.01824.x

Galtung, J., \& Höivik, T., (1971). Structural and Direct Violence: A Note on Operationalization, Journal of Peace Research, 8(1), 73 - 76. https://doi.org/10.1177/002234337100800108

Galtung, J., (1990). Cultural Violence. Journal of Peace Research, 27(3), 291 - 305. https://doi.org/10.1177/0022343390027003005

Gupta, A., \& Elby, A. (2011). Beyond Epistemological Deficits: Dynamic explanations of engineering students' difficulties with mathematical sense-making. International Journal of Science Education, 33(18), 2463-2488. https://doi.org/10.1080/09500693.2010.551551

Gupta, A., Elby, A., Turpen, C. A., \& Philip, T. M. (2016). The Dynamics of Perspective-taking in Discussions on Socio-technical Issues. 2016 ASEE Annual Conference \& Exposition. Retrieved from https://peer.asee.org/the-dynamics-of-perspective-taking-in-discussions-on-socio-technicalissues

Gupta, A., Hammer, D., \& Redish, E. F. (2010). The Case for Dynamic Models of Learners' Ontologies in Physics. Journal of the Learning Sciences, 19(3), 285-321.

Hammer, D., \& Elby, A. (2002). On the form of a personal epistemology. In B. K. Hofer \& P. R. Pintrich (Eds.), Personal epistemology: The psychology of beliefs about knowledge and knowing (pp. 169-190). Mahwah, N.J: L. Erlbaum Associates.

Haws, D. R. (2001). Ethics instruction in engineering education: A (mini) meta-analysis. Journal of Engineering Education, 90(2), 223-230. 
Herkert, J. R. (2005). Ways of thinking about and teaching ethical problem solving: Microethics and macroethics in engineering. Science and Engineering Ethics, 11(3), 373-385. https://doi.org/10.1007/s11948-005-0006-3

Hess, J. L., Strobel, J. and Brightman, A. O. (2017), The Development of Empathic PerspectiveTaking in an Engineering Ethics Course. J. Eng. Educ., 106: 534-563. doi:10.1002/jee.20175

Jaycox, H., Hess, J. L., Zoltowski, C. B., \& Brightman, A. O. (2014). Developing novel practices of somatic learning to enhance empathic perspective-taking for ethical reasoning and engineering design. In Frontiers in Education Conference (FIE), 2014 IEEE (pp. 1-5). IEEE.

Lachney, M., \& Banks, D. A. (2017). Teaching the Non-neutral Engineer: Pathways Toward Addressing the Violence of Engineering in the Classroom. Presented at the 2017 ASEE Annual Conference \& Exposition. Retrieved from https://peer.asee.org/teaching-the-non-neutralengineer-pathways-toward-addressing-the-violence-of-engineering-in-the-classroom

National Society of Professional Engineers. (2007). Code of Ethics. Retrieved December 31, 2017 , from https://www.nspe.org/resources/ethics/code-ethics

Norcia, V. di. (2002). Diverse knowledges and competing interests: An essay on socio-technical problem-solving. Science and Engineering Ethics, 8(1), 83-98. https://doi.org/10.1007/s11948002-0034-1

Philip, T. M., Gupta, A., Elby, A., \& Turpen, C. (2018). Why Ideology Matters for Learning: A Case of Ideological Convergence in an Engineering Ethics Classroom Discussion on Drone Warfare. Journal of the Learning Sciences, 27(2), 183-223. https://doi.org/10.1080/10508406.2017.1381964

Slaton, A. E. (2010). Race, rigor, and selectivity in US engineering: The history of an occupational color line. Harvard University Press.

Slaton, A. E. (2015). Meritocracy, Technocracy, Democracy: Understandings of Racial and Gender Equity in American Engineering Education. In International Perspectives on Engineering Education (pp. 171-189). Springer, Cham. https://doi.org/10.1007/978-3-319-16169-3_8

Smith III, J. P., diSessa, A. A., \& Roschelle, J. (1994). Misconceptions Reconceived: A Constructivist Analysis of Knowledge in Transition. Journal of the Learning Sciences, 3(2), 115. https://doi.org/10.1207/s15327809jls0302_1

Weick, K. E. (1990). The Vulnerable System: An Analysis of the Tenerife Air Disaster. Journal of Management, 16(3), 571-593. https://doi.org/10.1177/014920639001600304 